\title{
A Postpartum Rebound of Platelet Count in Patient with Type 2 Calreticulin -Mutant Essential Thrombocythemia: A Case Report
}

\author{
Abdulrahman Fadhl Al-Mashdali ( $\sim$ AAlmashdali@hamad.qa ) \\ Hamad Medical Corporation Department of Medical Education https://orcid.org/0000-0002-1393-5302 \\ Mohamed Yassin \\ NCCCR: National Center for Cancer Care and Research
}

\section{Research Article}

Keywords: Essential thrombocythemia, Rebound of platelet count, Calreticulin, Postpartum period, Pegylated Interferon Alfa, Case report

Posted Date: May 17th, 2021

DOl: https://doi.org/10.21203/rs.3.rs-391692/v1

License: (c) (i) This work is licensed under a Creative Commons Attribution 4.0 International License.

Read Full License 


\section{Abstract}

Essential thrombocythemia (ET) is an uncommon myeloproliferative neoplasm (MPN). It is more commonly encountered in females; around $20 \%$ of them are below 40 years old. The optimal management of ET during pregnancy and after delivery is still not well established. Here, we report a case of a young lady with ET who developed a marked rebound in her platelet count two weeks after delivery. She was on Pegylated Interferon (PEG-IFN) alfa 2-a during pregnancy, but she had stopped it on her own one month before delivery. We resumed her therapy, and subsequently, her platelet count reduced dramatically within four weeks to the acceptable range. This case emphasizes the importance of platelet count follow-up after delivery and outlines the management approach in such cases.

\section{Introduction}

Myeloproliferative neoplasms(MPNs), formerly named myeloproliferative disorders, are a group of diseases characterized by the excessive clonal production of red blood cells, platelets, or white blood cells, mainly in the bone marrow and occasionally in the liver and generally classified as Philadelphia positive MPNs which is represented by chronic myeloid leukemia (CML) [1]; and Philadelphia negative MPNs mainly ET, polycythemia vera(PV), and idiopathic myelofibrosis[2]. Essential thrombocythemia (ET) is an uncommon myeloproliferative neoplasm (MPN) characterized by the overproduction of platelets by bone marrow megakaryocytes[3]. Eventually, it may progress to myelofibrosis or acute myeloid leukemia[4].ET is usually sporadic and rarely can be familial[5]. Based on the latest world health organization (WHO) criteria for MPNs, ET is considered as a diagnosis of exclusion ( Table 1 )[6].

ET is more prevalent in females, and approximately $80 \%$ of them are above 40 years old. Nonetheless, ET still occurs in women within the reproductive age [7].ET increases the risk of thrombotic and bleeding events[8]. As we know, pregnancy is one of the hypercoagulable states [9]. Accordingly, pregnant women with ET are at high risk for thrombosis and its complications on the mother and fetus [10]. Thus, several guidelines and experts recommend ET management with interferon (IFN) therapy during pregnancy, especially in patients with a high risk for pregnancy termination[11].

Interestingly, many patients with ET may develop a rebound in platelet count during the postpartum course, which increases the risk of thrombosis during this prothrombotic period[11, 12]. Herein, we present a case of type 2 CALR -mutant Essential Thrombocythemia, who stopped her regular Pegulated Interferon Alfa-2a dose during pregnancy on her own and developed a marked rebound in her platelet counts during the postpartum period.

\section{Case Presentation}

A 30-year-old female was referred to us due to the persistent elevation in her platelet counts. The patient also reported fatiguability and generalized body pain for several weeks. Her past medical and family history was unremarkable. Complete blood count (CBC) revealed a platelet count of $2,030 \times 103 / \mu \mathrm{L}$. 
Other relevant laboratory results on presentation are shown below in Table 2. Physical examination was normal with no organomegaly or lymphadenopathy. MPNs, specifically ET, was suspected, and the workup was initiated to confirm that. The bone marrow biopsy result was consistent with ET. The tests for driver gene mutations were requested, and the patient was positive for a type $2,5 \mathrm{bp}$ insertion mutation within exon 9 of the calreticulin( CALR ) gene. Janus kinase 2 (JAK2V617F) and BCR-ABL 1 gene fusion mutations were negative.

The ET diagnosis was confirmed, and the patient started on Pegylated Interferon Alfa-2a at a dose of 135 micrograms weekly. Her platelet counts were controlled for several months after the initiation of therapy. However, during her second child's pregnancy, the patient stopped taking her weekly dose of Peginterferon Alfa-2a since the $20^{\text {th }}$ week of gestation without seeking medical advice. After that, she was delivered her child prematurely at the $24^{\text {th }}$ week of gestation through vaginal delivery. Her baby was intubated and admitted to the neonatal intensive care unit (NICU). Two weeks after delivery, during postnatal follow, the patient was found to have a platelet count exceeded 1.5 million. However, the period after delivery was uneventful. Fig. 1 below shows the platelet counts trend during her pregnancy and the early postpartum period. We resumed Peginterferon Alfa-2a at a dose of 135 micrograms. After four weeks of follow-up, her platelet count decreased to $684 \times 103 / \mathrm{L}$. Recently, the patient presented to the emergency department with a platelet count of $2538 \times 103$ /L. No complications were identified. Again, the reason for the rebound in her platelet count was noncompliant with Peginterferon Alfa-2a. We added a one-month course of hydroxyurea $100 \mathrm{mg}$ twice a day to suppress the bone marrow production of platelets. Her latest platelet is currently controlled at $778 \times 103 / \mathrm{L}$ on Peginterferon alfa-2a $135 \mathrm{mcg}$ weekly with regular follow-up at the outpatient clinic until the moment.

\section{Discussion}

ET remains the most encountered MPN in young women within the reproductive age [13]. As mentioned in the introduction, ET patients who get pregnant are at higher risk for thrombotic complications. It was found that the rate of first-trimester spontaneous abortions and premature deliveries in ET patients were higher than that in healthy individuals [11]. Additionally, pregnancy complications, like intrauterine growth restriction and placental abruption, are common in pregnant ladies with ET [14]. Treatment of ET during pregnancy has shown a considerable improvement in maternal and fetal outcomes [15]. Interferon-alpha therapy is considered the safest drug of choice for ET treatment during pregnancy [15]. Our patient had stopped her Peginterferon alfa by the end of the first half of pregnancy. Unfortunately, her platelet counts were increased, and she delivered her baby prematurely at the 24th week of gestation, which may support the relation between ET treatment and pregnancy outcomes.

Janus kinase 2 (JAK2V617F), Myeloproliferative leukemia (MPL), and calreticulin( CALR ) gene mutations have been detected in the vast majority of patients with ET[16]. JAK2(V617F)mutation and MPL gene mutation have been reported in up to $60 \%$ and $5 \%$ of ET cases, respectively[16].Most of the ET cases which were negative for JAK2 and MPL genetic mutation found to be positive for CALR mutation[16]. However, approximately $10-15 \%$ of cases are negative for all three mutated genes "triple- 
negative" [17]. Calreticulin (CALR) is a calcium-binding protein located abundantly in the endoplasmic reticulum and involved in variable biological functions[18]. CALR regulates the folding process of newly synthesized glycoprotein and contributes to calcium hemostasis [18]. It was recently found that CALR mutation independently activates the thrombopoietin receptor, promoting megakaryocyte proliferation and subsequently the development of ET[19]. There are two main types of CALR gene mutation, A 52-bp deletion (type 1 mutation) and a 5-bp insertion (type 2 mutation)[19]. In ET, type 1 mutation is related to a higher risk of transformation to myelofibrosis. Whereas, type 2 variant, which was detected in our patient, is strongly linked to ET with a more indolent disease course, higher platelet counts, and lower risk of thrombosis [19].

Typically, platelet counts decline during pregnancy and eventually return to pre-gestational level within the first 4-6 weeks after delivery[9]. The mechanism for this phenomenon is not clearly explained[9]. Nonetheless, this decline in platelet counts may play a protective role against thrombosis during pregnancy [9]. As has been mentioned above, many patients with ET develop a rebound in platelet count after delivery. Experts suggest that platelet count should be repeated after six weeks of delivery [15]. Of note, the platelet count's rebound may occur as early as two weeks postpartum, like in our patient and other reported cases [20]. There is still no enough data regarding the rebound management in platelet count during the postpartum period. The cytoreductive medication was initiated in some cases soon after delivery, whereas others were managed conservatively with a spontaneous decline of platelet count[20]. The management should be individualized according to the disease-related factors and risk of thrombosis[20]. We managed our patient by resuming her usual dose of Peginterferon Alfa-2a, resulting in a dramatic response with more than $50 \%$ reduction in her platelet count within a short period.

\section{Conclusion}

Our patient developed a significant rebound in her platelet count during the early postpartum period. She did not develop any thrombotic or bleeding complications during that time. Evidence for management of platelet rebound after delivery is still scarce. We treated our patient successfully with IFN therapy. Accordingly, we highly suggest this therapy, considering its safety profile and efficacy to lower platelet count, to prevent thrombosis during this prothrombotic period.

\section{Declarations}

\section{Acknowledgments}

The authors would like to acknowledge Qatar national library (QNL)for this publication's funding and the HMC internal medicine residency program for scientific support.

Funding This work was funded by Qatar National Library (QNL)

Conflicts of interest The authors have no conflict of interest to declare 
Ethics approval This case report was approved by the Hamad Medical Corporation's Medical Research Center ( Protocol number: MRC -04-21-284)

Consent to participate Not applicable

Consent for publication Written informed consent was taken from the patient.

Availability of data and material Not applicable

Code availability Not applicable

Authors' contributions AA contributed to data collection, literature review, and manuscript writing. MY contributed to the literature review and final revision of the manuscript as a mentor

\section{References}

1. Turkina A, Wang J, Mathews V, et al (2020) TARGET: a survey of real-world management of chronic myeloid leukaemia across 33 countries. Br J Haematol 190:869-876

2. Yassin MA, Taher A, Mathews V, et al (2020) MERGE: A Multinational, Multicenter Observational Registry for Myeloproliferative Neoplasms in Asia, including Middle East, Turkey, and Algeria. Cancer Med 9:4512-4526

3. Yassin MA, Nehmeh SA, Nashwan AJ, et al (2020) A study of 18F-FLT positron emission tomography/computed tomography imaging in cases of prefibrotic/early primary myelofibrosis and essential thrombocythemia. Medicine (Baltimore). https://doi.org/10.1097/MD.0000000000023088

4. Beer PA, Green AR (2009) Pathogenesis and management of essential thrombocythemia. Hematology Am Soc Hematol Educ Program 621-628

5. Al-Dewik N, Ben-Omran T, Zayed H, Trujillano D, Kishore S, Rolfs A, Yassin MA (2019) Clinical Exome Sequencing unravels new disease-causing mutations in the myeloproliferative neoplasms: A pilot study in patients from the state of Qatar. Gene 689:34-42

6. Arber DA, Orazi A, Hasserjian R, Thiele J, Borowitz MJ, Le Beau MM, Bloomfield CD, Cazzola M, Vardiman JW (2016) The 2016 revision to the World Health Organization classification of myeloid neoplasms and acute leukemia. Blood 127:2391-2405

7. McNally RJ, Roman E, Cartwright RA (1999) Leukemias and lymphomas: time trends in the UK, 198493. Cancer Causes Control 10:35-42

8. Barbui T, Thiele J, Passamonti F, et al (2011) Survival and disease progression in essential thrombocythemia are significantly influenced by accurate morphologic diagnosis: an international study. J Clin Oncol 29:3179-3184

9. How J, Leiva O, Bogue T, et al (2020) Pregnancy outcomes, risk factors, and cell count trends in pregnant women with essential thrombocythemia. Leuk Res 98:106459 
10. Griesshammer M, Struve S, Barbui T (2008) Management of Philadelphia negative chronic myeloproliferative disorders in pregnancy. Blood Rev 22:235-245

11. Griesshammer M, Sadjadian P, Wille K (2018) Contemporary management of patients with BCRABL1-negative myeloproliferative neoplasms during pregnancy. Expert Rev Hematol 11:697-706

12. Griesshammer M, Sadjadian P, Wille K (2018) Contemporary management of patients with BCRABL1-negative myeloproliferative neoplasms during pregnancy. Expert Rev Hematol 11:697-706

13. Passamonti F, Randi ML, Rumi E, et al (2007) Increased risk of pregnancy complications in patients with essential thrombocythemia carrying the JAK2 (617V>F) mutation. Blood 110:485-489

14. Chow EY, Haley LP, Vickars LM (1992) Essential thrombocythemia in pregnancy: platelet count and pregnancy outcome. Am J Hematol 41:249-251

15. Robinson SE, Harrison CN (2020) How we manage Philadelphia-negative myeloproliferative neoplasms in pregnancy. $\mathrm{Br} \mathrm{J}$ Haematol 189:625-634

16. Rumi E, Pietra D, Ferretti V, et al (2014) JAK2 or CALR mutation status defines subtypes of essential thrombocythemia with substantially different clinical course and outcomes. Blood 123:1544-1551

17. Tefferi A, Lasho TL, Finke CM, Knudson RA, Ketterling R, Hanson CH, Maffioli M, Caramazza D, Passamonti F, Pardanani A (2014) CALR vs JAK2 vs MPL-mutated or triple-negative myelofibrosis: clinical, cytogenetic and molecular comparisons. Leukemia 28:1472-1477

18. Michalak M, Groenendyk J, Szabo E, Gold LI, Opas M (2009) Calreticulin, a multi-process calciumbuffering chaperone of the endoplasmic reticulum. Biochem J 417:651-666

19. Pietra D, Rumi E, Ferretti VV, et al (2016) Differential clinical effects of different mutation subtypes in CALR-mutant myeloproliferative neoplasms. Leukemia 30:431-438

20. Hashimoto Y, Hosoda R, Omura H, Tanaka T (2021) Marked Rebound of Platelet Count in the Early Postpartum Period in a Patient with Essential Thrombocythemia. Case Rep Hematol 2021:6633790

\section{Tables}

Table 12016 WHO diagnostic criteria for ET * 


\section{WHO ET criteria}

\section{Major criteria}

1. Platelet count $\geq 450 \times 10^{9} / \mathrm{L}$

2. BM biopsy showing proliferation mainly of the megakaryocyte lineage with increased numbers of enlarged, mature megakaryocytes with hyperlobulated nuclei. No significant increase or left shift in neutrophil granulopoiesis or erythropoiesis and very rarely minor (grade 1) increase in reticulin fibers

3. Not meeting WHO criteria for $B C R-A B L 1, C M L, P V, P M F$, myelodysplastic syndromes, or other myeloid neoplasms

4. Presence of JAK2, CALR, or MPL mutation

Minor criterion

Presence of a clonal marker or absence of evidence for reactive thrombocytosis

How to diagnose ET?

Diagnosis of ET requires meeting all four major criteria or the first three major criteria and the minor criterion.

* Adapted from Arber et al. Blood 2016;127:2391-2405

Table 2 Laboratory findings on the first presentation 


\begin{tabular}{|llll|}
\hline Group & Detail & Value w/Units & Normal Range \\
\hline General Hematology & WBC & $15.20 \times 10^{\wedge} 3 / \mathrm{uL}$ & $4.00-10.00$ \\
\hline General Hematology & RBC & $4.0 \times 10^{\wedge} 6 / \mathrm{uL}$ & $3.8-4.8$ \\
\hline General Hematology & Hgb & $12.0 \mathrm{gm} / \mathrm{dL}$ & $12.0-15.0$ \\
\hline General Hematology & Hct & $36.4 \%$ & $36.0-46.0$ \\
\hline General Hematology & MCV & $91.0 \mathrm{fL}$ & $83.0-101.0$ \\
\hline General Hematology & Platelet & $2,030 \times 10^{\wedge} 3 / \mathrm{uL}$ & $150-400$ \\
\hline General Hematology & ANC & $11.2 \times 10^{\wedge} 3 / \mathrm{uL}$ & $2.0-7.0$ \\
\hline General Hematology & Lymphocyte & $2.8 \times 10^{\wedge} 3 / \mathrm{uL}$ & $1.0-3.0$ \\
\hline General Hematology & Monocyte & $1.0 \times 10^{\wedge} 3 / \mathrm{uL}$ & $0.2-1.0$ \\
\hline General Hematology & Eosinophil & $0.2 \times 10^{\wedge} 3 / \mathrm{uL}$ & $0.0-0.5$ \\
\hline General Hematology & Basophil & $0.10 \times 10^{\wedge} 3 / \mathrm{uL}$ & $0.02-0.10$ \\
\hline Coagulation & vWF Ag & $66.6 \%$ & \\
\hline Coagulation & vWF Activity & $35.2 \mathrm{~seconds}$ & \\
\hline Blood Chemistry & C-reactive protein & $<5 \mathrm{mg} / \mathrm{L}$ & \\
\hline Blood Chemistry & Creatinine & $50 \mathrm{umol} / \mathrm{L}$ & $44-80$ \\
\hline Blood Chemistry & Sodium & $137 \mathrm{mmol} / \mathrm{L}$ & $136-145$ \\
\hline Blood Chemistry & Potassium & $6.1 \mathrm{mmol} / \mathrm{L}$ & $3.5-5.1$ \\
\hline Blood Chemistry & Adjusted Calcium & $2.56 \mathrm{mmol} / \mathrm{L}$ & $2.20-2.55$ \\
\hline Blood Chemistry & Albumin & $34.0 \mathrm{gm} / \mathrm{L}$ & $35.0-52.0$ \\
\hline Blood Chemistry & ALT & $9 \mathrm{U} / \mathrm{L}$ & $0-33$ \\
\hline Blood Chemistry & AST & $15 \mathrm{U} / \mathrm{L}$ & $0-32$ \\
\hline & & & \\
\hline
\end{tabular}

( Abbreviations : WBC: White blood cell; RBC: Red blood cell; Hgb: Hemoglobin; Hct: Hematocrit; MCV: Mean corpuscular volume; ANC : Absolute Neutrophil Count ; vWF :von Willebrand factor (VWF) ; ALT: alanine aminotransferase ; AST : aspartate aminotransferase )

\section{Figures}




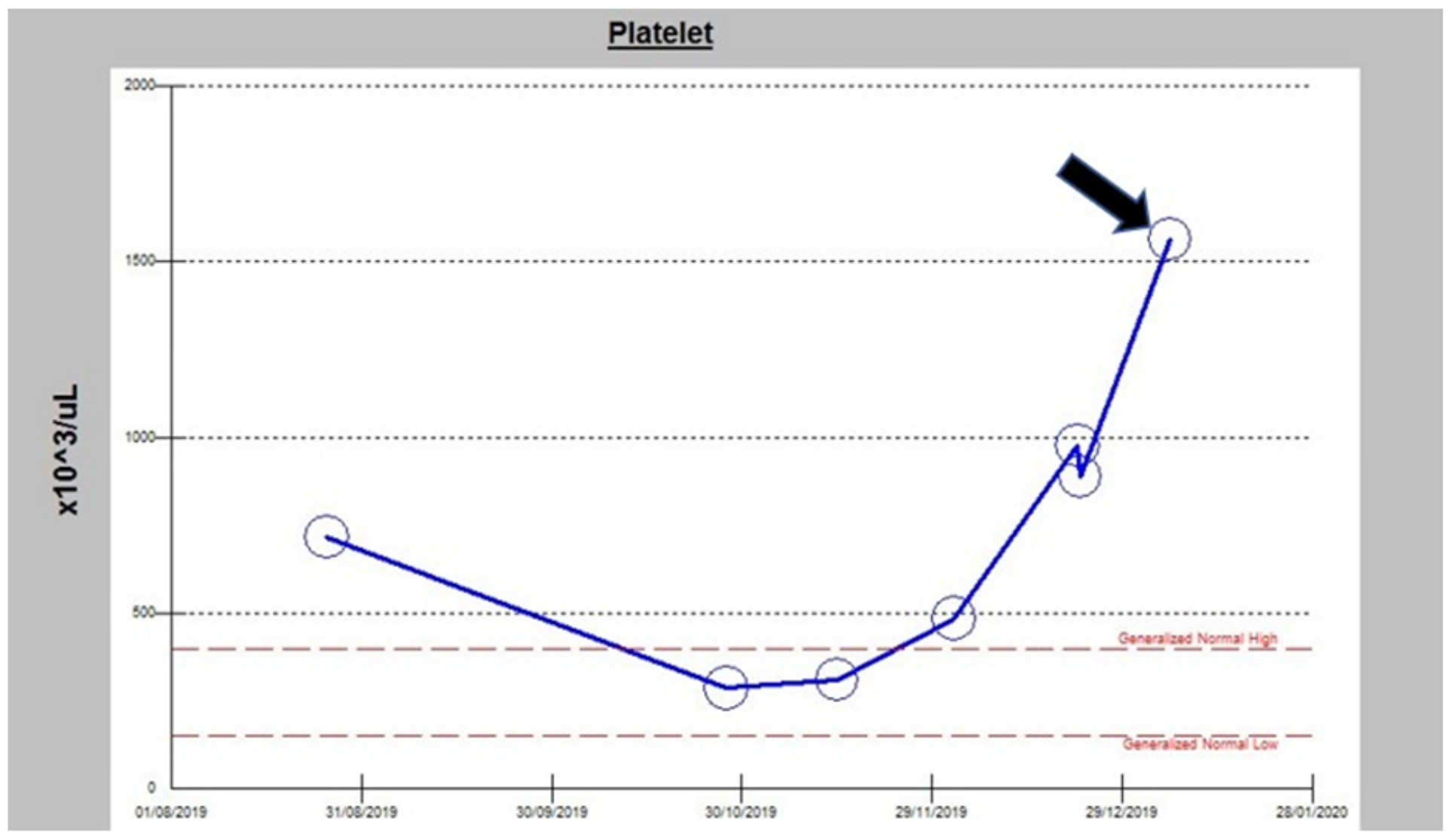

\section{Figure 1}

Trend in the patient platelet counts during the pregnancy and postpartum period, the black arrow shows the rebound in the platelet count during the postpartum period

\section{Supplementary Files}

This is a list of supplementary files associated with this preprint. Click to download.

- CAREchecklistEnglish2013.pdf 